\title{
What does a Northern Blot have to do with my medical practice? The story of The Oncologist
}

\begin{abstract}
When Dr. Rafael Rosell's invitation arrived asking for a brief account of the origins of the international journal, The Oncologist, we interpreted this to be a gracious and collegial gesture from a dear friend and esteemed colleague. We were, however, quick to learn that Dr. Rosell actually wanted an article on the birth and first five years of life of the journal. Although it is true that The Oncologist is one of the world's fastest growing medical periodicals, we wondered how we could distill five years of experience into a few pages of text. Nevertheless, Dr. Rosell, a most persuasive editor in his own right, wanted a short history, and he wanted it now! The following musings are a humble attempt to satisfy his kind request.
\end{abstract}

\section{A NEED IS DISCOVERED}

Advances in our understanding of the biology and molecular biology of cancer proceed at a breath-taking pace. In fact, the keystone has just been hoisted into the archway of human biology with the sequencing of the human genome. These are heady times for laboratory investigators.

New drugs and new drug combinations which once arrived at a trickle, now pour forth from pharmaceutical drug pipelines; pipelines which, we are told, are bulging at the seams with putative new drugs.

Couple this with the explosive communication possibilities which the Internet provides, and it is easy to understand why many busy physicians feel that one of the most daunting challenges is to keep abreast of key advances which should be translated into their personal medical practice.

There was a time, when one could attend an annual meeting during which all that was important would be conveniently served up. The major oncology meetings, however, have grown so large that they are caught in a gridlock imposed by their sheer size. At the same time, some cancer medicine journals have, for some practitioners, become another challenge. As one communitybased oncologist remonstrated, «What does a Northern Blot have to do with my medical practice?»

It was in this historic context that The Oncologist was born five years ago. The intention was simply to provide a peer-reviewed journal of relevance for the practitioner. Our Founding Editors framed their thoughts with the following enunciation of its Mission and our Beliefs.

Rev Oncología 2000; 2: 229-230

\section{MISSION AND BELIEFS}

The practice of oncology and hematology is more challenging than ever before. Physicians are charting new territories in cancer patient care and practice management.

The Oncologist was established by oncologists to help physicians better manager their practices in a changing and challenging environment, to guard against the future and ensure their patient's rights to the best health care possible. On its editorial board serve some of the finest oncologists from around the globe. Since The Oncologist is committed to the multimodality care of cancer patients, the editorial board consists of medical, surgical, and radiation oncologists. They were carefully chosen based primarily on their documented leadership in furthering cancer care and their dedication to fostering its translation into community practice.

The Oncologist is devoted to medical and practice issues for surgical, radiation and medical oncologists and is designed specifically for the busy practitioner entrusted with the care of adult or pediatric cancer patients. With emphasis on clear, concise interpretation, this bimonthly, international peer-reviewed journal publishes original papers, reviews and commentaries addressing the multimodality diagnosis, treatment and quality of life of the cancer patient. Manuscripts are reviewed by two or more experts in the field and, when accepted, are published with haste, generally within twelve weeks. When a contribution is of such relevance as to significantly impact public health, authors may request Fast Track Review for a Rapid Communication, in which case an editorial decision will be made within two weeks of submission. The journal's articles are meant to impact the practice of oncology and to facilitate significant communication in the introduction of new medical treatments and technologies. Emphasizing the interpretation rather than the data, The Oncologist's Editor-in-Chief (Dr. Bruce A. Chabner) and Founding Editors (Drs. Frank M. Balis, Gregory A. Curt, Eli Glatstein, John E. Niederhuber, H. M. Pinedo, Valerie W. Rusch and Peter M. Schlag) believed that the various oncology subspecialists should share the same information base and read the same journal. As cancer specialists, we should resist the trend to capitulate our responsibilities in disease management to payers, gatekeepers, and hospital administrators. It is up to us to defend the patient's needs and rights and to assure that the patient has an advocate. In order to do so, we have to be united and fully informed. We pledge to put the 
best and latest information on cancer management before our readership, to help them for the future, and do their best as a team for every patient.

To this end, The Oncologist challenges its readers to understand what is new and better, to glimpse the future, not only in terms of research, but also in terms of new team approaches to disease management. In short, we want our readers to explore how cancer medicine could be and will be practiced now in the years ahead.

\section{THE JOURNAL'S CURRENT STATUS}

In a precarious medical publishing environment in which three out of four new journals die within three years of birth, The Oncologist has, within its first five years, earned a global circulation of 17,000 for its English edition and a Spanish edition will soon be available to 2,000 physicians in Spain. Translation into other widely used languages is currently under review. Index Medicus/Medline readily awarded The Oncolo gist inclusion in its premier database of the United States National Library of Medicine. Last November, the journal launched its website that is powered by diesel search engines which easily enable the reader to access the world's medical literature with the click of a mouse key. Astonishingly, more than 40,000 readers visit www.TheOncologist.com each month. Indeed, The Oncologist appears to be addressing a real need.

\section{THE JOURNAL'S FUTURE PLANS}

The Senior Editors, recently joined by Dr. Raphael E. Pollock, plan to increase the utility of the journal's website by adding, after careful review, additional websites of particular relevance to our physician readership. The Editors will also open a Patient's Reading Lounge with helpful literature and web references for the many patients who also frequently visit the website. The Editors continue to seek what's new and important, recruiting key opinion leaders to author manuscripts for peer-reviewed publication consideration. They identify current controversies and seek to report on them in a fair and balanced fashion. The journal has also embarked upon an ambitious identification of key topics that warrant coverage in greater depth. The first two of these freestanding journal supplements have recently been published to widespread acclaim. They are: 1. Translational Research: the Role of vascular endo thelial growth factor (VEGF) in Tumor Angiogenesis.

2. Radiation Therapy, Anemia, and Outcomes: Current Concepts, Future Strategies.

\section{SECRETS OF SUCCESS}

What then are the journal's «secrets of success»? What factors have enabled The Oncologist to thrive? Here are the most salient ones.
A real need was discovered. Oncologists want and need a journal that is authoritative but not authoritarian; a strictly peer-reviewed forum designed to meet the special needs of the busy community-based practitioner.

A team of oncology experts representing medical, surgical, radiation and pediatric oncologists, banded together with a commitment to craft a journal for the "guy in the trenches.» In so doing, the Senior Editors have become a confraternity in which a common and important mission binds them together. The Senior Editors, in turn, have recruited superb members to the journal's editorial board whose job it is to author and to solicit authorship and to critically review submitted manuscripts.

Enlightened corporate executives have given vital support to the journal, and they have done so without any considerations except for the gratitude with which we announce their unrestricted educational grants. They realize that enlightened physicians are essential for the furtherance of medical practice. They simply see it as «the right thing to do», whether or not it is good for business.

To single out any individuals for special credit would instantly place one in jeopardy of omitting many others who are also deserving of great credit and high praise. Nevertheless, it is easy to state that the cornerstone of the journal's success is derived from the leadership of our Founding and Senior Editors. Realizing the great power and responsibilities of editorship, they daily rise to their tasks with a sense of dedication that makes it a joy to be in their association. They keep the journal on course, not allowing it to stray from the mission upon which we originally embarked.

The poet admonished us to "Dream no little dreams, for they have no magic to move men's souls.» The big dreams which the editors have dreamed for The Onco logist would never see the light of day were it not for the indefatigable support of the journal's managing editor, Dr. Ann Murphy, our editorial assistant, Lisa Tempalski, and the fine staff of AlphaMed Press who Ann inspires to deliver personal attention to the entreaties of authors and readers whilst they continue to meet every deadline. Therein lies another secret of the journal's success: a publisher dedicated to excellence. On behalf of the Senior Editors and the editorial board we express our appreciation and admiration to them.

Our greatest appreciation is reserved for cancer patients and you, our readers. It is, after all, for them and for you that we dedicate ourselves and The Onco logist.

We rise to salute you.

Martin J. Murphy, Jr.

Executive Editor. The Oncologist. 